
Kidney
Bloód Pressure
Research

Kidney Blood Press Res 2013;37:451-457

DOI: 10.1159/000355725

(c) 2013 S. Karger AG, Basel

www.karger.com/kbr

Accepted: September 05, 2013

1423-0143/13/0375-0451\$38.00/0

This is an Open Access article licensed under the terms of the Creative Commons AttributionNonCommercial 3.0 Unported license (CC BY-NC) (www.karger.com/OA-license), applicable to the online version of the article only. Distribution permitted for non-commercial purposes only.

\title{
Observations of Changes of Blood Pressure Before and after Neurosurgical Decompression in Hypertensive Patients with Different Types of Neurovascular Compression of Brain Stem
}

\author{
Peter Legrady Erika Voros $^{\mathrm{b}} \quad$ Dora Bajcsi $^{\mathrm{a}} \quad$ Imola Fejes $^{\mathrm{a}} \quad$ Pal Barzo $^{c}$ \\ Gyorgy Abraham ${ }^{a}$
}

aFirst Department of Medicine, University of Szeged; 'bepartment of Radiology, University of Szeged;

'Department of Neurosurgery, University of Szeged, Szeged, Hungary

\section{Key Words}

Brain stem • Hypertension • Neurovascular • Compression types

\begin{abstract}
Aims: The neurovascular pulsatile compression of the rostral ventrolateral medulla can be divided into different subtypes. The posterior inferior cerebellar artery and/or vertebral artery can compress either the rostral ventrolateral medulla or the cranial nerves IX and X or both and on left, right or both sides. Methods: It was retrospectively investigated whether the types of neurovascular compression can influence blood pressure values. Data from 13 resistant hypertensive patients after decompression were investigated. Results: Six patients had 2 compressions, two had only medulla compression, four had only nerve compression on the left side and one had 2 compressions on both sides. There was no correlation between the types of compression and the levels of blood pressure, either before or after the decompression. Both, systolic and diastolic blood pressures and pulse pressure also decreased in all cases after the decompression but the change was significant only in the group with 2 compressions on the left side. Conclusion: According to our data, in a severe hypertension not responding to conventional antihypertensive therapy, the surgical decompression of the brain stem independently of the types of neurovascular compression could guarantee a decrease of blood pressure and improved sensitivity to antihypertensive medication.
\end{abstract}




\section{Kidney \\ Blood Pressure Research}

Kidney Blood Press Res 2013;37:451-457

\begin{tabular}{l|l}
\hline DOI: $10.1159 / 000355725$ & C 2013 S. Karger AG, Basel
\end{tabular}

Published online: October 18, 2013

www.karger.com/kbr

Legrady/Voros/Bajcsi/Fejes/Barzo/Abraham: Types of Brain Stem Compression and Blood Pressure

\section{Introduction}

Hypertension (HT) is therapeutically resistant when the blood pressure (BP) level cannot be normalized with a diuretic-containing triple drug combination administered at a maximum dose [1]. It is true that most of these cases are not really resistant and it is more likely that the therapeutic choice or the compliance or sometimes both of them are inappropriate. The exact prevalence of resistant HT is difficult to determine, it ranges from $5 \%$ to $30 \%$ depending on populations and the circumstances of data collection [2]. In a patient with HT that can only be managed with multiple drug combination after excluding all the so-called conventional secondary etiological factors, the neurovascular pulsatile compression (NVPC) of the rostral ventrolateral medulla (RVLM) on the left side may be the background reason. In such cases the neurovascular decompression (NVD) can decrease the blood pressure effectively [3-5].

\section{Central regulation}

The RVLM located in the brain stem is the centre of the neuronal regulation of blood pressure (BP) and heart rate (HR). Cranial nerve IX (the glossopharyngeal nerve) carries afferent signals from the aortic arch and cranial nerve $X$ (the vagus nerve) does the same from the carotid sinus. The left nerve $\mathrm{X}$ also carries afferent signals from the mechanoreceptors in the left atrial wall [6]. The sympathicoexcitatory, so called C1 neurons are situated in the RVLM, about $1 \mathrm{~mm}$ below the surface of the brain stem. Efferent fibres lead from there into the preganglionic sympathetic neurons located in the intermediolateral column of the thoracic spinal cord. Discharging of these neurons increases systemic sympathetic activity [7]. An activation of the $\mathrm{C} 1$ neurons elevates the BP, whereas deactivation of it decreases the BP $[8,9]$. The caudal medulla oblongata is a depressor region that can inhibit the RVLM directly.

\section{Neurovascular pulsatile compression}

Trigeminal, glossopharyngeal neuralgias and hemifacial spasm are caused by NVPC by elongated and/or not typically placed arteries. Around thirty years ago it was reported first time that NVPC of the RVLM also can be behind of the arterial HT. The posterior inferior cerebellar artery (PICA) and/or the vertebral artery (VA) can compress the root-entry zone of cranial nerves IX and $\mathrm{X}$ and/or the $\mathrm{C} 1$ neurons containing the retro-olivary sulcus near to the root-entry zone on the left side [5, 10-13].

Objective

It was retrospectively investigated whether is there an association between the types of NVPC and the systolic and diastolic (BP) before and after NVD and/or between the types and the changes of BP after NVD.

Ethics committee approval

Approved by the Human Investigation Review Board, University of Szeged, Albert SzentGyorgyi Medical and Pharmaceutical Centre (2/2007).

\section{Methods}

Between 2000 and 2004, using a neurosurgical database, a magnetic resonance investigation combined with angiography (MRA) was performed in 50 resistant primary HT cases. The criterion for MRA was to exclude previously all the possible secondary causes of resistant HT.

For the MRA a 1T Sigma Horizont LX General Electric device with a 3D spoiled gradient echo /3D time-of-flight technique was used. The volume thickness was $60-70 \mathrm{~mm}$ and the slice thickness was $1 \mathrm{~mm}$. The time of echo was $2.9 \mathrm{msec}$, the time of repetition was $33 \mathrm{msec}$ and the flip angle was 20 degrees. The maximum intensity projection was reconstructed in an optional plane. The requirement for a positive MRA 


\section{Kidney Blood Pressure Research}

Legrady/Voros/Bajcsi/Fejes/Barzo/Abraham: Types of Brain Stem Compression and Blood Pressure

Table 1. Distribution of types of neurovascular pulsatile compression

\begin{tabular}{|c|c|c|c|c|c|c|c|c|}
\hline \multicolumn{3}{|c|}{ Type BS ( $n=15)$} & \multicolumn{3}{|c|}{ Type N (n=12) } & \multicolumn{3}{|c|}{ Type $D(n=17)$} \\
\hline $\begin{array}{l}\text { BSL } \\
n=12\end{array}$ & $\begin{array}{l}\text { BSR } \\
n=0\end{array}$ & $\begin{array}{l}\text { BSB } \\
n=3\end{array}$ & $\begin{array}{l}\mathrm{NL} \\
\mathrm{n}=12\end{array}$ & $\begin{array}{l}\mathrm{NR} \\
\mathrm{n}=0\end{array}$ & $\begin{array}{l}\text { NB } \\
n=0\end{array}$ & $\begin{array}{l}\text { DL } \\
n=15\end{array}$ & $\begin{array}{l}\text { DR } \\
n=1\end{array}$ & $\begin{array}{l}\text { DB } \\
n=1\end{array}$ \\
\hline
\end{tabular}

(NVPC) among all the 50 patients by magnetic resonance investigation combined with angiography. Six patients had no any NVPC

finding was a touch between the looping arteries and the surface of the RVLM at the root entry-exit zone of nerves IX and X, or between the looping arteries and the cranial nerves IX and X on the left side. All the MRA readings were done by the same expert radiologist.

Based on possible anatomical variations according to MRA, different groups were formed. In group BS the NVPC affected only the brain stem (on right side: BSR, on left side: BSL, on both sides: BSB). In group $\mathrm{N}$ the NVPC affected only the nerves IX-X (on right side: NR, on left side: NL, on both sides: NB). In group D dual NVPC could be observed affecting both the brain stem and the nerves (on right side: DR, on left side: DL, on both sides: DB).

NVDs were performed under anaesthesia. Following a retromastoidal suboccipital craniotomy on the left side, identifying the anatomical structures a tissue-friendly haemostatic sponge (SpongostanTM, Johnson \& Johnson Medical Ltd.) was placed between the arteries and the nerves or the surface of the RVLM. All the procedures were performed in the Department of Neurosurgery in Szeged.

$\mathrm{BP}$ readings were recorded at the time of the last visit, a few days before the NVD, and at the end of 1st postoperative week in the 1st Department of Internal Medicine in Szeged which is one of the Excellence Centers of the European Society of Hypertension. BP readings were performed by manual sphygmomanometer. Means of two measurements were calculated.

Data were compared statistically by means of parametric one-way analysis of variance (ANOVA). The relationships between the types of the compressions and the BP levels were analysed with Pearson's correlation test. Probability levels $\mathrm{p}<0.05$ were taken as significant. Means \pm SD are reported.

\section{Results}

According to the MRA from the 50 patients no kind of NVPC was found in 6 cases. Leftsided neurovascular contact was found in 43 cases, and right-sided contact in 1 case. Fifteen patients had type BS, 12 patients had type $\mathrm{N}$ and 17 had type $\mathrm{D}$ compression (Table 1 ).

NVD was recommended to severe primary HT patients with neurovascular contacts only on the left side. In the cases of left-sided neurovascular contact with only mild-tomoderate increased BP level the NVD was not recommended. NVDs were performed on the 18 patients who agreed to surgery. Only 13 of these were patients of the Szeged 1st Department of Internal Medicine and the others were only sent for the surgical procedure from other hospitals, therefore data concerning them could not be collected retrospectively. Therefore only the data on the 13 patients was analysed in this work. In the 1st Department of Internal Medicine NVD was recommended not just in a case of severe HT but a positive family history of fatal or non-fatal cardio-/cerebrovascular complications was also required. Of course all possible secondary causes were excluded in all cases prior to MRA.

In the course of the 18 NVD procedures, the MRA findings were confirmed in all but one case using the neurosurgical database. In this case, the MRA indicated NVPC of the rootentry zone of cranial nerves IX and X and of the RVLM caused by the PICA and the VA on the left side. However, NVD revealed only NVPC of the RVLM caused by the VA.

Both the systolic and the diastolic BP (SBP and DBP) levels decreased significantly after the NVD, as did the pulse pressure (PP). The need for the antihypertensive medication was calculated as the sum of the number of different drugs administered. It also decreased in most of the cases after NVD (Table 2). 


\section{Kidney \\ Blood Pressure Research}

Table 2. Data of 13 operated patients. ( $F=$ female, $M=$ male)

\begin{tabular}{cccccccccc}
\hline Gender & $\begin{array}{c}\text { Age } \\
\text { (years) }\end{array}$ & $\begin{array}{c}\text { Time } \\
\text { of HT } \\
\text { (years) }\end{array}$ & $\begin{array}{c}\text { BMI } \\
(\mathrm{kg} / \mathrm{m} 2)\end{array}$ & $\begin{array}{c}\text { BP before } \\
\text { NVD (mm } \\
\text { Hg) }\end{array}$ & $\begin{array}{c}\text { BP after } \\
\text { NVD (mm } \\
\text { Hg) }\end{array}$ & $\begin{array}{c}\text { PP } \\
\text { before } \\
\text { NVD } \\
\text { (mm Hg) }\end{array}$ & $\begin{array}{c}\text { PP after } \\
\text { NVD } \\
\text { (mm Hg) }\end{array}$ & $\begin{array}{c}\text { No of } \\
\text { comb. } \\
\text { before } \\
\text { NVD }\end{array}$ & $\begin{array}{c}\text { No of } \\
\text { comb. } \\
\text { after NVD }\end{array}$ \\
\hline F & 52 & 16 & 29.9 & $190 / 120$ & $156 / 100$ & 70 & 56 & 8 & 4 \\
F & 45 & 5 & 26.5 & $220 / 125$ & $150 / 80$ & 95 & 70 & 4 & 3 \\
M & 50 & 5 & 29.0 & $190 / 105$ & $130 / 75$ & 85 & 55 & 5 & 6 \\
M & 31 & 18 & 23.1 & $210 / 100$ & $130 / 80$ & 110 & 50 & 4 & 6 \\
F & 47 & 15 & 22.8 & $280 / 150$ & $140 / 80$ & 130 & 60 & 6 & 3 \\
M & 53 & 15 & 29.4 & $240 / 150$ & $120 / 80$ & 90 & 40 & 3 & 1 \\
F & 47 & 12 & no data & $240 / 145$ & $145 / 90$ & 95 & 55 & 6 & 4 \\
F & 40 & 10 & 35.4 & $200 / 120$ & $170 / 120$ & 80 & 50 & 6 & 5 \\
F & 35 & 5 & 33.6 & $160 / 100$ & $140 / 90$ & 60 & 50 & 6 & 4 \\
F & 33 & 13 & 22.0 & $300 / 140$ & $143 / 92$ & 160 & 51 & 4 & 4 \\
F & 55 & 35 & 27.1 & $200 / 110$ & $154 / 90$ & 90 & 64 & 7 & 5 \\
F & 50 & 17 & 28.9 & $210 / 100$ & $158 / 80$ & 110 & 78 & 7 & 4 \\
F & 34 & 14 & 25.5 & $200 / 140$ & $140 / 80$ & 60 & 60 & 4 & 4 \\
\hline
\end{tabular}

Table 3. Distribution of types of neurovascular pulsatile compression among the operated

\begin{tabular}{ccccccccc}
\hline \multicolumn{3}{c}{ Type BS $(\mathrm{n}=2)$} & \multicolumn{3}{c}{ Type N $(\mathrm{n}=4)$} & \multicolumn{3}{c}{ Type D (n=7) } \\
\hline BSL & BSR & BSB & NL & NR & NB & DL & DR & DB \\
$n=2$ & $n=0$ & $n=0$ & $n=4$ & $n=0$ & $n=0$ & $n=6$ & $n=0$ & $n=1$ \\
\hline
\end{tabular}
13 patients

Table 4. Blood pressure and pulse pressure values in operated patients by neurovascular pulsatile compression subgroups. ${ }^{*} p<0.05$ after $v s$. before; ${ }^{* *} p<0.01$ after $v s$. before; mean \pm SD

\begin{tabular}{lcccccc}
\hline & \multicolumn{2}{c}{ SBP $(\mathrm{mm} \mathrm{Hg})$} & \multicolumn{2}{c}{ DBP $(\mathrm{mm} \mathrm{Hg})$} & \multicolumn{2}{c}{ PP (mm Hg) } \\
\cline { 2 - 6 } & Before NVD & After NVD & Before NVD & After NVD & Before NVD & After NVD \\
\hline DL & $201 \pm 11$ & $* * 137 \pm 5$ & $116 \pm 7$ & $* 87 \pm 4$ & $85 \pm 7$ & $* 50 \pm 2$ \\
BSL & $240 \pm 40$ & $147 \pm 7$ & $130 \pm 20$ & $85 \pm 5$ & $110 \pm 20$ & $62 \pm 2$ \\
NL & $225 \pm 50$ & $143 \pm 21$ & $125 \pm 19$ & $93 \pm 19$ & $100 \pm 43$ & $50 \pm 8$ \\
DB & 240 & 145 & 145 & 90 & 95 & 55 \\
\hline
\end{tabular}

The type D NVPC was observed most frequently among the 11 operated patients, 6 of them on the left side and 1 on both sides. However in the latter case NVD was performed only on the left side (Table 3).

The significance of differences of mean BP values before and after the NVD only derived from the significant differences observed in group DL. The decreases of BP were not statistically significant in other goups and subgroups (Table 4).

All the NVDs were successful, no serious complications of it or death connected with it were observed. Only transient vertigo appeared in some cases after the decrease of BP levels.

No correlation was found between either the types of NVD and the pressure or the number of antihypertensive agents. However the change of BP after NVD was only significant in cases of dual NVPC on the left side. The absolute BP values of these patients did not differ significantly from the others.

\section{Discussion}

The RVLM is the major centre for the regulation of the systemic BP and HR via sympathetic nerve activity (SNA). The cranial nerve IX carries afferent signals from the aortic arch, whereas cranial nerve $X$ does so from the carotid sinus. The left nerve $X$ also carries afferent signals from the mechanoreceptors in the left atrial wall [6]. The sympathico-excitatory 


\section{Kidney Blood Pressure Research}

\begin{tabular}{l|l}
\hline Kidney Blood Press Res 2013;37:451-457 \\
\hline DOI: $10.1159 / 000355725$ & (c) 2013 S. Karger AG, Basel
\end{tabular}

Published online: October 18, 2013

www.karger.com/kbr

Legrady/Voros/Bajcsi/Fejes/Barzo/Abraham: Types of Brain Stem Compression and Blood Pressure

catecholamine synthetising C1 neurons are situated in the RVLM, probably $1 \mathrm{~mm}$ below the surface of the brain stem. These catecholaminergic C1 neurones have an important role in maintaining resting sympathetic vasomotor tone and arterial HT. Efferent fibres lead from there into the preganglionic sympathetic neurons located in the intermediolateral column of the thoracic spinal cord. The discharge of these neurons increases the SNA [8]. Stimulation of the $\mathrm{C} 1$ neurons with glutamate elevates the $\mathrm{BP}$, whereas cooling or destruction of this region decreases the BP, as does stimulation with gamma-amino butyric acid $[3,4,9]$.

The NVPC at the root-entry zone of cranial nerves IX and X can cause a temporary oxygen deficiency, which blocks signal transmission into the nucleus tractus solitarii (NTS). Therefore it will not be activated and the $\mathrm{C} 1$ neurons released from the physiological inhibition caused by the NTS [4]. According to another theory, direct excitation of the C1 neurons by arterial pulsation can surpass the inhibitory signals from the NTS, causing a permanent discharge of the excitatory neurons [14].

Microanatomical investigations performed by Naraghi et al. of samples from cadavers of HT patients did not reveal either demyelinization or degeneration provoked by NVPC [4]. In that work they described 3 types of NVPC: type I (monovascular): compression by only the VA or only the PICA; type II (vertebral): compression by only the VA; and type III (combination): compression by both the VA and the PICA. Our grouping was similar to theirs.

In a recent Japanese study it has been reported, similar to many previous studies, that prevalence of NVPC of the RVLM was significantly higher in the group of patients with primary HT $(35 \%)$ than in the normotensive group $(13 \%)(\mathrm{p}<0.05)[3,4,14-18]$. A recent study using high-resolution MRI scans with $1 \mathrm{~mm}$ slices showed that the frequency of NVPC of the RVLM was clearly and significantly higher in patients with primary HT (73.5\%) than in patients with secondary HT (12.5\%) [19].

Since Jannetta's papers many studies have confirmed that an NVD of the RVLM on the left side decreases the BP value, even lasting for many years [6, 9, 20, 21]. Among others Sasaki et al. reported successful NVD in cases of 4 refractory HT patients [22]. Three of them had hemifacial spam. Our patients did not show any symptoms of cranial rhizopathies. In a previous work we described that 2 years after a successful NVD the BP values and the therapeutic efforts were decreased compared to the pre-operative period [23].

In primary HT patients with NVPC on the left side of the RVLM there is a significantly increased plasma norepinephrine level confirming the elevated SNA [24, 25]. More evidence for increased SNA is the increased muscle SNA in primary HT patients with NVPC of the RVLM [26].

German authors have presented their results of $14 \mathrm{HT}$ patients with more than 3 antihypertensive drugs who underwent NVD procedure. Not only the BP but also SNA decreased after NVD [27].

A Japanese team have reported a case of a patient, with resistant HT and NVPC of the RVLM on the left side, who experienced notable BP reduction by clonidine therapy [28]. However, unfortunately not all the NVPC HT patients react to central-acting antihypertensive agents, otherwise discussion about a possible beneficial neurosurgical procedure would not be necessary.

According to the literature NVD is usually performed in HT patients with at least 3 different antihypertensive drugs. In our cases the mean number of antihypertensive agents were 5 .

\section{Conclusion}

In conclusion, in cases of severe resistant primary HT, without any possible so-called conventional secondary causes, not responding to multiple combinations of therapy, NVPC of the brain stem should be considered and MRA performed. If NVPC is confirmed by MRA, successful neurosurgical NVD of the brain stem on the left side can guarantee a BP reduction 


\section{Kidney \\ Blood Pressure Research}

Kidney Blood Press Res 2013;37:451-457

\begin{tabular}{l|l}
\hline DOI: $10.1159 / 000355725$ & (C) 2013 S. Karger AG, Basel
\end{tabular}

Published online: October 18, 2013

www.karger.com/kbr

Legrady/Voros/Bajcsi/Fejes/Barzo/Abraham: Types of Brain Stem Compression and Blood Pressure

with less or same need for antihypertensive medication. From our results NVPCs on the left side of the brain stem may relate to HT, but the type of the NVPC does not correlate to the $\mathrm{BP}$ values. Therefore, perhaps, neither the location nor the number of NVPCs on the left side, affect the degree of the SNA. From this point of view the fact of NVPC on the left side is the most important not its type. A continuous pulsatile stimulation of the RVLM on the left side may lead to a tonic increase in SNA and HT, but it cannot explain all the refractory HTs. A new question arises here: if NVD may affect the BP and the SNA, is it really a case of a primary HT or is it one of an unconventional secondary form? More data are needed to decide this.

\section{Conflict of Interests}

There is no conflict of interest.

\section{References}

1 Chobanian AV, Bakris GL, Black HR, Cushman WC, Green LA, Izzo JL Jr, Jones DW, Materson BJ, Oparil S, Wright JT Jr, Roccella EJ; National Heart, Lung, and Blood Institute Joint National Committee on Prevention, Detection, Evaluation, and Treatment of High Blood Pressure; National High Blood Pressure Education Program Coordinating Committee: The Seventh Report of the Joint National Committee on Prevention, Detection, Evaluation, and Treatment of High Blood Pressure: the JNC 7 report. JAMA 2003;289:2560-2572.

-2 Schmieder RE, Redon J, Grassi G, Kjeldsen SE, Mancia G, Narkiewicz K, Parati G, Ruilope L, van de Borne P, Tsioufis C: ESH position paper: renal denervation - an interventional therapy of resistant hypertension. J Hypertens 2012;30:837-841.

-3 Jannetta PJ, Segal R, Wolfson SK Jr: Neurogenic hypertension: etiology and surgical treatment I. Observation in 53 patients. Ann Surg 1985;201:391-398.

4 Naraghi R, Gaab MR, Walter GF, Kleineberg B: Arterial hypertension and neurovascular compression at the ventrolateral medulla. A comparative microanatomical and pathological study. J Neurosurg 1992;77:103-

112.

-5 Watters MR, Burton BS, Turne GE, Cannard KR: MR screening for brain stem compression in hypertension. Am J Neuroradiol 1996;17:217-221.

-6 Levy EI, Clyde B, McLaughlin MR, Jannetta PJ: Microvascular decompression of the left lateral medulla oblongata for severe refractory neurogenic hypertension. Neurosurgery 1998;43:1-9.

7 Schreihofer AM, Stornetta RL, Guyenet PG: Regulation of sympathetic tone and arterial pressure by rostral ventrolateral medulla after depletion of C1 cells in rat. J Physiol 2000;529:221-236.

8 Geiger H, Naraghi R, Schobel HP, Frank H, Sterzel RB, Fahlbusch R: Decrease of blood pressure by ventrolateral medullary decompression in essential hypertension. Lancet 1998;352:446-449.

-9 Jannetta PJ, Gendell HM: Clinical observation on etiology of essential hypertension. Surg Forum 1979;30:431-432.

10 Naraghi R, Schuster H, Toka HR, Bähring S, Toka O, Oztekin O, Bilginturan N, Knoblauch H, Wienker TF, Busjahn A, Haller H, Fahlbusch R, Luft FC: Neurovascular compression at the ventrolateral medulla in autosomal dominant hypertension and brachydactyly. Stroke 1997;28:1749-1755.

-11 Nakamura T, Osawa M, Uchiyama S, Iwata M: Arterial hypertension in patients with left primary hemifacial spasm is associated with neurovascular compression of the left rostral ventrolateral medulla. Eur Neurol 2007;57:150-155.

12 Coffee RE, Nicholas JS, Egan BM, Rumboldt Z, D'Agostino S, Patel SJ: Arterial compression of the retroolivary sulcus of the medulla in essential hypertension: a multivariate analysis. J Hypertens 2005;23:20272031.

13 Tamura Y, Kondo A, Tanabe H, Sasaki S: Microvascular decompression for refractory neurogenic hypertension: case report. No Shinkei Geka 2006;34:65-71. 


\section{Kidney \\ Blood Pressure Research}

Kidney Blood Press Res 2013;37:451-457

\begin{tabular}{l|l}
\hline DOI: $10.1159 / 000355725$ & (c) 2013 S. Karger AG, Basel
\end{tabular}

Published online: October 18, 2013

www.karger.com/kbr

arady/Voros/Bajcsi/Fejes/Barzo/Abraham: Types of Brain Stem Compression and Blood Pressure

14 Gajjar D, Egan B, Curè J, Rust P, VanTassel P, Patel SJ: Vascular compression of the rostral ventrolateral medulla in sympathetic mediated essential hypertension. Hypertension 2000;36:78-82.

15 Yamamoto I, Yamada S, Sato 0: Microvascular decompression for hypertension-clinical and experimental study. Neurol Med Chir (Tokyo) 1991;31:1-6.

16 Morimoto S, Sasaki S, Miki S, Kawa T, Itoh H, Nakata T, Takeda K, Nakagawa M, Naruse S, Maeda T: Pulsatile compression of the rostral ventrolateral medulla in hypertension. Hypertension 1997;29:514-518.

17 Morise T, Horita M, Kitagawa I, Shinzato R, Hoshiba Y, Masuya H, Suzuki M, Takekoshi N: The potent role of increased sympathetic tone in pathogenesis of essential hypertension with neurovascular compression. J Hum Hypertens 2000;14:807-811.

-18 Sakuma T, Morimoto S, Aota Y, Takahashi N, Toyoda N, Kosaki A, Maehara M, Tanigawa N, Ikeda K, Sawada S, Iwasaka T: Efficacy of clonidine in patients with essential hypertension with neurovascular contact of the rostral ventrolateral medulla. Hypertens Res 2010;33:633-637.

19 Goldmann A, Herzog T, Schaeffer J, Muehling M, Haubitz B, Haller H, Becker H, Radermacher J: Prevalence of neurovascular compression in patients with essential and secondary hypertension. Clin Nephrol 2007;68:357-366.

20 Jannetta PJ, Hamm IS, Jho HD, Saiki I: Essential hypertension caused by arterial compression of the left lateral medulla: a follow-up. Perspect Neurol Surg 1992;3:107-125.

21 Morimoto S, Sasaki S, Takeda K, Furuya S, Naruse S, Matsumoto K, Higuchi T, Saito M, Nakagawa M: Decreases in blood pressure and sympathetic nerve activity by microvascular decompression of the rostral ventrolateral medulla in essential hypertension. Stroke 1999;30:1707-1710.

-22 Sasaki S, Tanda S, Hatta T, Morimoto S, Takeda K, Kizu O, Tamaki S, Saito M, Tamura Y, Kondo A: Neurovascular decompression of the rostral ventrolateral medulla decreases blood pressure and sympathetic nerve activity in patients with refractory hypertension. J Clin Hypertens (Greenwich) 2011;13:818-820.

23 Legrady P, Voros E, Bajcsi D, Sonkodi S, Barzo P, Abraham G: Neurovascular pulsatile compression and neurosurgical decompression of the rostral ventrolateral medulla in medically resistant hypertensive patients. Kidney Blood Press Res 2008;31:433-437.

24 Morimoto S, Sasaki S, Itoh H, Nakata T, Takeda K, Nakagawa M, Furuya S, Naruse S, Fukuyama R, Fushiki S: Sympathetic activation and contribution of genetic factors in hypertension with neurovascular compression of the rostral ventrolateral medulla. J Hypertens 1999;17:1577-1582.

25 Makino Y, Kawano Y, Okuda N, Horio T, Iwashima Y, Yamada N, Takamiya M, Takishita S: Autonomic function in hypertensive patients with neurovascular compression of the ventrolateral medulla oblongata. J Hypertens 1999;17:1257-1263.

26 Sendeski MM, Consolim-Colombo FM, Leite CC, Ribira MC, Lessa P, Krieger EM: Increased sympathetic nerve activity correlates with neurovascular compression at the rostral ventrolateral medulla. Hypertension 2006;47:988-995.

-27 Frank H, Heusser K, Geiger H, Fahlbusch R, Naraghi R, Schobel HP: Temporary reduction of blood pressure and sympathetic nerve activity in hypertensive patients after microvascular decompression. Stroke 2009;40:47-51.

28 Morimoto S, Aota Y, Sakuma T, Ichibangase A, Ikeda K, Sawada S, Iwasaka T: Efficacy of clonidine in a patient with refractory hypertension and chronic renal failure exhibiting neurovascular compression of the rostral ventrolateral medulla. Hypertens Res 2009;32:227-228. 